\title{
Genetic polymorphisms of matrix metalloproteinases and protein levels in chronic obstructive pulmonary disease in a Mexican population
}

\begin{abstract}
Aim: To evaluate association of single nucleotide polymorphisms (SNPs) in the MMP1, MMP2, MMP9 and MMP12 genes and serum MMP-2 and MMP-9 levels in smoking chronic obstructive pulmonary disease (COPD) patients. Materials \& methods: Genotyping using real-time PCR in 330 smokers with COPD (COPD), 658 smokers without COPD (SNC) and 150 nonsmokers (NCNS), the analysis of samples used was $\chi^{2}$ test. Using ELISA, the proteins were evaluated. Multiple comparisons were made by ANOVA. Results: rs243864 (OR: 7.44; 95\% Cl: 3.62-15.26) and rs11646643 (OR: 1.58; 95\% Cl: 1.07-2.34) of the MMP-2 gene and rs3918253 (OR: 1.72; $95 \% \mathrm{Cl}: 1.08-2.71$ ) of the MMP-9 gene, were associated with the risk of COPD. Serum MMP-2 level in the COPD group was lower compared with SNC $(p<0.05)$. Serum MMP-9 level was elevated in the COPD group compared with SNC $(p<0.05)$. Conclusion: Polymorphisms in MMP2 and MMP9 but not in MMP1 and MMP12 are associated with the risk of COPD in the Mexican mestizo population.
\end{abstract}

Keywords: COPD • genetic susceptibility • MMP2 • MMP9 • polymorphisms

Chronic obstructive pulmonary disease (COPD) is characterized by chronic inflammation of the airways and lung parenchyma; it is associated with remodeling and degradation of the extracellular matrix (ECM) and loss of elastin fibers in lung tissue [1-3]. It is caused by prolonged exposure to noxious particles and gases; exacerbations and comorbidities contribute to severity and are a significant cause of morbidity and mortality [4-6]. It has been proposed that an interaction exists between genetic and environmental factors that influence individual susceptibility to COPD [7]. The main environmental risk factor is cigarette smoke, which initiates and maintains the inflammatory response in the lungs and airways $[8,9]$. With respect to genetic factors the extracellular matrix metalloproteinases (MMPs) have an important role due to these proteases are involved in various physiological and pathological processes [10-13]. In humans, 24 enzymes have been described that can alter components of the ECM [14]. MMPs, mainly MMP-1, MMP-2, MMP-9 and MMP-12, play an essential role in repair and remodeling processes in lung tissue [15-17]. Recent genetic studies have implicated MMP genes and endogenous inhibitors called tissue inhibitors of metalloproteinases (TIMPs) in the pathogenesis of COPD; an imbalance of MMPs and TIMPs contributes to disease development $[18,19]$. Single nucleotide polymorphisms (SNPs) associated with COPD have been described in the $M M P-1, M M P-2$, $M M P-9$ and $M M P-12$ genes in several populations [20,21]. The existence of polymorphisms in genes determines the different levels of expression between individuals who create different disease phenotypes in a given population [22] In this study, the genotype frequencies of 12 polymorphisms of the $M M P-1, M M P-2$, $M M P-9$ and $M M P-12$ genes were determined in the Mexican mestizo population with the aim of establishing the association of SNPs with disease. Additionally, the serum levels of the MMP-2 and MMP-9 proteins were determined in smokers with and without COPD, as well as in nonsmokers. The additional aim
Jazmín Hernández-Montoya', Julia Pérez-Ramos², Martha Montaño ${ }^{3}$, Alejandra Ramírez-Venegas ${ }^{4}$, Raúl H Sansores ${ }^{4}$, Gloria PérezRubio ${ }^{5}$, Mónica VelázquezUncall $^{4}$, Angel Camarena ${ }^{5}$, Carlos Ramos*,3 \& Ramcés Falfán-Valencia**,5

'Doctorado en Ciencias Biológicas y de la Salud, Universidad Autónoma Metropolitana Xochimilco-IztapalapaCuajimalpa, México DF, México ${ }^{2}$ Departamento de Sistemas Biológicos, Universidad Autónoma MetropolitanaXochimilco, México DF, México ${ }^{3}$ Departamento de investigación en fibrosis pulmonar, Instituto Nacional de Enfermedades Respiratorias Ismael Cosío Villegas (INER), México DF, México ${ }^{4}$ Departamento de Investigación en Tabaquismo y EPOC, Instituto Nacional de Enfermedades Respiratorias Ismael Cosío Villegas (INER), México DF, México ${ }^{5}$ Laboratorio HLA, Instituto Nacional de Enfermedades Respiratorias Ismael Cosío Villegas (INER), México DF, México *Author for correspondence: Tel.: +52 (55) 54871700 ext. 5257 carlos.ramos26@yahoo.com.mx **Author for correspondence: Tel: +52 (55) 54871700 ext. 5152 rfalfanv@iner.gob.mx 
of this study was to evaluate whether BMI and packyears variables are associated with these protein levels for it became multiple comparisons.

\section{Methods}

The study observational, comparative cross-sectional was conducted with patients belonging to the Department of Research on Smoking and COPD, National Institute of Respiratory Diseases Ismael Cosío Villegas (INER) of Mexico City. The total population of participants was 1138, of which 988 were smokers: 330 patients with COPD from the COPD Clinic, 658 smokers without COPD (SNC) from the Smoking Cessation Clinic and 150 healthy nonsmoker subjects without clinical evidence of respiratory diseases. Previously, a part of these study groups were analyzed for other genes [23,24]. All participants were Mexican by descent (Mexican parents and grandparents), over 40 years in age and the smokers had smoked at least ten cigarettes a day for 10 years or more. The diagnosis of COPD was based on spirometry data; following the GOLD diagnostic criteria, the control subjects had a postbronchodilator FEV1/FVC ratio equal to or greater than $70 \%$ while the cases diagnosed with COPD had a $\mathrm{FEV}_{1} / \mathrm{FVC}$ ratio of less than $70 \%$. The patients were diagnosed by pulmonology specialists at the INER COPD clinic. COPD susceptibility was evaluated for 12 SNP polymorphisms in four MMP genes in the Mexican mestizo population. The associated genotypes in comparison of the cases and controls were determined in the group of 150 nonsmoker subjects, as were the serum levels of metalloproteinases- 2 and metalloproteinases-9 encoded by genes in which the associated SNPs are located.
This protocol was evaluated and accepted by the Science and Research Bioethics Committees of the INER in Mexico. All participants were initially invited to participate, and those who agreed signed a letter of informed consent created for that purpose.

\section{DNA extraction}

The blood samples were processed in the HLA laboratory of INER to obtain genomic DNA using a commercial kit (BDtract Genomic DNA Isolation Kit, Maxim Biotech, Inc., CA, USA). The DNA was quantified by UV spectrophotometry using NanoDrop 2000 equipment (Thermo Scientific, DE, USA). Contamination with organic compounds and proteins was determined by establishing the ratio of 260/240 and 260/280 readings, respectively. Samples were considered free of contaminants in both cases when the ratio was between 1.7 and 2.0.

\section{Selection of SNPs}

The selection process of the evaluated SNPs included a literature review of previous reports of genetic association of SNPs in MMP genes with COPD in Caucasian and Asian populations, using the NCBI (National Center for Biotechnology Information) database and including scientific articles published between 2007 and 2013. For the four included genes, tag SNP selection was performed with HaploView version 4.2, using the minor allele frequency (MAF) $\geq 10 \%$ and $\mathrm{r}^{2} \geq 0.80$ in the Caucasian population as a reference. A total of 12 SNPs were selected, and data including the chromosome location and polymorphism base change are shown in Table 1.

\begin{tabular}{|c|c|c|c|c|c|}
\hline \multirow{2}{*}{$\begin{array}{l}\text { Gene/ } \\
\text { chromosome }\end{array}$} & \multirow[t]{2}{*}{ SNP } & \multirow[t]{2}{*}{ Gene location } & \multicolumn{2}{|c|}{ Allele } & \multirow[t]{2}{*}{ Tagged SNPs } \\
\hline & & & Change & Ancestral & \\
\hline \multirow[t]{3}{*}{$M M P-1 / 11$} & rs470215 & 3'UTR & $A / G$ & $A$ & \multirow[t]{3}{*}{ rs5854, rs470747 } \\
\hline & rs7125062 & Intronic & $\mathrm{C} / \mathrm{T}$ & $\mathrm{T}$ & \\
\hline & rs2071232 & Intronic & $\mathrm{C} / \mathrm{T}$ & $\mathrm{T}$ & \\
\hline \multirow[t]{4}{*}{$M M P-2 / 16$} & rs243839 & Intronic & $A / G$ & G & $\begin{array}{l}\text { rs865094, rs183112, rs243849, } \\
\text { rs243843, rs243840, }\end{array}$ \\
\hline & rs243835 & Intronic & $\mathrm{C} / \mathrm{T}$ & C & rs243836, rs243834 \\
\hline & rs243864 & (-790) promoter & $\mathrm{G} / \mathrm{T}$ & $\mathrm{T}$ & rs243865, rs243866 \\
\hline & rs11646643 & Intronic & $A / G$ & G & rs1477017, rs9302671, rs17301608 \\
\hline \multirow[t]{2}{*}{ MMP-9/20 } & rs3918253 & Intronic & $\mathrm{C} / \mathrm{T}$ & C & \multirow[t]{2}{*}{ rs3918256 } \\
\hline & rs3918278 & Intronic & $A / G$ & G & \\
\hline \multirow[t]{3}{*}{$M M P-12 / 11$} & rs12808148 & Intronic & $\mathrm{C} / \mathrm{T}$ & $\mathrm{T}$ & \\
\hline & rs17368659 & Intronic & $\mathrm{G} / \mathrm{T}$ & G & \\
\hline & rs2276109 & Intronic & $A / G$ & $A$ & \\
\hline
\end{tabular}




\section{Genotyping}

For genotyping by real-time PCR, $3 \mu \mathrm{l}$ of DNA was used at a concentration of $15 \mathrm{ng} / \mu \mathrm{l}$. The amplification conditions were as follows: $50^{\circ} \mathrm{C}$ for $2 \mathrm{~min}, 95^{\circ} \mathrm{C}$ for 10 min, followed by 40 cycles of $95^{\circ} \mathrm{C}$ for $15 \mathrm{~s}$ and a final cycle of $60^{\circ} \mathrm{C}$ for $1 \mathrm{~min}$. The alleles and genotypes of the polymorphisms were characterized by real-time PCR (7300 Real Time PCR System, Applied Biosystems, CA, USA) via allelic discrimination using commercial Taqman probes at $20 \times$ concentration (Applied Biosystems). In addition three controls without template (contamination controls) were included for each genotyping plate and $1 \%$ of the samples included in the study were genotyped in duplicate as control allele assignment.

\section{Obtaining serum levels of MMP-2 \& MMP-9 with ELISA}

Based on the results from the genetic association analysis, the serum levels were measured for total MMP-2 protein with commercial ELISA kits (R\&D Systems, MN, USA) and for MMP-9 (BioLegend Systems, CA, USA).

Readings were obtained using the $\mathrm{iMark}^{\mathrm{TM}}$ Microplate Absorbance Reader (Bio-Rad, CA, USA).

\section{Statistical analysis}

To determine the SNPs associated with the risk of COPD, the frequencies of the genotypes of the two study groups were compared, and the odds ratio (OR) was calculated with a 95\% CI using Epi Info version 7.1.2 (CDC, GA, USA). The ancestral allele was used a reference for each of the polymorphisms, and population data for the frequencies of the SNPs studied in the Mexican population residing in Los Angeles, California, USA (HapMap-MEX), obtained from the HapMap project (International HapMap Project), were included. Differences between the groups were analyzed via $\chi^{2}$ test. Linkage disequilibrium $\left(\mathrm{r}^{2}\right.$ $>80$ ) and analysis of haplotypes were performed with HaploView version 4.2. To determine the relationship of the genotypes with the variables BMI, age, gender, packyears and the ratio in the percentage of the FEV1/ FVC ratio post bronchodilator, a binary logistic regression was performed with SPSS 21 (IL, USA). To determine the association of the protein levels with disease, genotype and other variables, factorial ANOVA was used, and comparisons were made between the groups using the Tukey-Kramer test. For the analysis, NCSS version 9 was used (UT, USA).

\section{Results}

\section{Characteristics of the study population}

The demographic, smoking and lung function characteristics of the study groups are shown in Table 2. There was a greater ratio of men to women in the COPD group (3.07:1, M:W), whereas in the SNC group, the ratio of women was greater with respect to men (1.06:1, W:M); a similar ratio was observed in the NCNS group (1.83:1, W:M). COPD individuals were older than the SNC individuals $(\mathrm{p}<0.0001)$; the opposite pattern was observed with BMI, which was greater in the SNC group compared with that in the COPD group $(p<0.0001)$. The packyears was significantly greater in the COPD group compared with the SNC group $(\mathrm{p}<0.0001)$. The mean age of the NCNS individuals was similar to those of the COPD and SNC groups; the BMI of the NCNS group was similar to that of the SNC group. The lung function of the COPD groups was diminished in comparison to that of the SNC group; as expected, the lung function of the NCNS group was normal and differed slightly from that of the SNC group. Variables for which statistically significant differences were found between the groups were considered for logistic regression correction.

\section{Polymorphisms associated with genetic susceptibility to COPD}

To determine the genetic susceptibility to COPD, the genotype frequencies of 12 SNPs selected in four MMP genes were compared. Polymorphisms associated with the risk of COPD were found in the MMP-2 and $M M P-9$ genes. No statistically significant associations of risk were found in SNPs evaluated in the MMP-1 and MMP-12 genes. All polymorphisms complied with Hardy-Weinberg equilibrium (HW, p $>0.05)$. Three SNPs associated with increased risk of COPD were identified: the homozygous GG genotype rs243864 (10.3 vs $1.51 \%$, OR: 7.44) and the GG genotype rs11646643 (15.45 vs $10.33 \%$, OR: 1.58 ) of the MMP-2 gene as well as the TT genotype rs3918253 (11.21 vs $6.83 \%$, OR: 1.72 ) of MMP-9. Interestingly, two SNPs were associated with reduced risk of disease: the heterozygous AG genotype of the rs 11646643 polymorphism of the $M M P-2$ gene (44.24 vs $54.4 \%$, OR: 0.66) and the CC genotype of the MMP-9 gene ( 49.09 vs $57.75 \%$ ); however, only two genotypes retain association after Bonferroni's correction (rs243864/ GG $\mathrm{p}=1.20 \mathrm{E}-09$ and $\mathrm{rs} 11646643 / \mathrm{AG} \mathrm{p}=3.08 \mathrm{E}-02$ ).

The frequencies of all of the genotypes evaluated as well as those described for HapMap Mexican mestizos are found in Table 3. Supplementary Table 2 includes p-values, OR and 95\% CI for significant and not significant data. Based on the previously described results in the genetic association analysis, genotyping was conducted on the two SNPs most strongly associated with COPD risk (MMP-2 rs243864 and $M M P-9$ rs3918253) in a population comparison group composed of 150 nonsmokers without COPD and 
Table 2. Demographic data of the study subjects.

\begin{tabular}{|c|c|c|c|c|}
\hline Characteristics & COPD $(n=330)$ & SNC $(n=658)$ & NCNS $(n=150)$ & p-value \\
\hline Gender (\%), M/F & $76 / 24$ & $48 / 52$ & $35 / 64$ & $<0.0001$ \\
\hline Age (years) & $67 \pm 9$ & $53 \pm 9$ & $62 \pm 13$ & $<0.0001$ \\
\hline BMI $\left(\mathrm{kg} / \mathrm{m}^{2}\right)$ & $25.47 \pm 5$ & $27.12 \pm 4$ & $28 \pm 6$ & $<0.0001$ \\
\hline Packyears & $40 \pm 38$ & $27 \pm 22$ & - & $<0.0001$ \\
\hline \multicolumn{5}{|l|}{ Lung function $(\%)$ : } \\
\hline - FEV (predicted) & $60 \pm 27$ & $98 \pm 49$ & $90 \pm 19$ & $<0.0001$ \\
\hline - FVC (predicted) & $83 \pm 25$ & $96 \pm 17$ & $84 \pm 18$ & $<0.0001$ \\
\hline$-\mathrm{FEV}_{1} / \mathrm{FVC}$ & $56 \pm 15$ & $79 \pm 8$ & $89 \pm 11$ & $<0.0001$ \\
\hline \multicolumn{5}{|c|}{$\begin{array}{l}\text { Data are reported as the media } \pm \text { SD. The } p \text {-value for comparing COPD and SNC were by statistical test } \chi^{2} \text { test. } \\
\text { Smokers with COPD (COPD), smokers without COPD (SNC) and nonsmokers (NCNS). } \\
\text { BMI: Body mass index; COPD: Chronic obstructive pulmonary disease; FEV;: Forced expiratory volume in } 1 \mathrm{~s} \text {; FVC: Forced vital capacity; } \\
\text { M/F: Male/female. }\end{array}$} \\
\hline
\end{tabular}

without exposure to smoke from burning biomass. The genotypic frequency (GF) percentages for the rs243864 polymorphism of the $M M P-2$ gene were TT (56.66\%), GT (36.66\%) and GG (7.03\%) and were CC (59.33\%), CT (24\%) and TT (16.66\%) for the rs3918253 polymorphism of the $M M P-9$ gene.

Comparison of frequencies in the study groups with population values

The genotype frequencies of the 12 SNPs in four MMP genes of the SNC group were compared with the described HapMap frequencies in Mexicans born in Los Angeles. It was identified that the frequency of the CT genotype of the rs 7125062 polymorphism of the $M M P-1$ gene in the SNC group was slightly reduced when compared with the population data from HapMap (49.24 vs $58.0 \%$ ), contrary to what was observed with the frequency of the TT genotype of the same polymorphism, which was slightly elevated in the SNC group. For the $M M P-2$ gene, the CC genotype frequency of the rs243835 polymorphism was different from the reported HapMap frequency (26.59 vs 38\%), as was the CT genotype frequency of the rs 3918253 polymorphism in the MMP-9 gene (35.41 vs 25\%). Interestingly, the CC genotype frequency of the rs 12808148 polymorphism in the MMP-12 gene of the SNC group that represents Mexican mestizos by descent was $12 \%$, but that genotype was not reported in the resident Mexican population in Los Angeles, California, by the HapMap project.

A binary logistic regression was performed considering each of the polymorphisms and their respective genotypes as dependent variables and the post bronchodilator lung function value as an independent variable. An association was only found for rs3918253 of the MMP-9 gene under the CC versus CT + TT model, where a significant $\mathrm{p}$ value $(\mathrm{p}=0.001, \beta=-0.017,95 \%$ CI: 0.97-0.99) was obtained with the post bronchodilator FEV1/FVC ratio.

\section{SNP haplotypes in MMP genes}

Haplotype analysis was performed on polymorphisms in the $M M P-1, M M P-2, M M P-9$ and $M M P-12$ genes; they were analyzed by chromosomal location. No haplotypes were found to be associated with EPOC $\left(\mathrm{r}^{2}\right.$ < 80); graphs of the haplotypes formed for $M M P-1$, $M M P-2, M M P-9$ and $M M P-12$ genes are shown in Supplementary Figure 1.

Relationship of the serum levels of the MMP-2 \& MMP-9 proteins with COPD

The serum levels of the MMP-2 and MMP-9 proteins of the COPD, SNC and NCNS groups were measured by ELISA using commercial kits. The serum level of MMP-2 of the COPD group was significantly lower compared with that of the SNC group (446.72 vs $983.44 \mathrm{ng} / \mathrm{ml}, \mathrm{p}<0.05)$. There was a statistically significant difference between the MMP-2 serum levels of the SNC and NCNS groups (983.44 vs $660.33 \mathrm{ng} / \mathrm{ml}$, $\mathrm{p}<0.05)$, as shown in Figure 1; in contrast, the serum level of the MMP-9 protein was elevated in the COPD group compared with that of the SNC group (1468.69 vs $771.64 \mathrm{ng} / \mathrm{ml}, \mathrm{p}<0.05)$. There was a statistically significant difference between the SNC and NCNS groups $(771.64 \mathrm{ng} / \mathrm{ml}$ vs $1,394.39 \mathrm{ng} / \mathrm{ml}, \mathrm{p}<0.05)$. No association was found between the serum levels of MMP-2 and MMP-9 proteins and other variables.

\section{Discussion}

In this genetic association study, we showed that three (rs243864, rs11646643 and rs3918253) of the 12 evaluated polymorphisms in the $M M P-1, M M P$ 2, $M M P-9$ and $M M P-12$ genes are associated with genetic susceptibility for COPD in the Mexican mestizo population. GG rs243864 (OR: 7.44) and GG rs11646643 (OR: 1.58) in MMP-2 and TT rs3918253 (OR: 1.72) in the MMP-9 gene are associated with the risk of COPD. 
Table 3. Genotype frequencies of MMP-1, MMP-2, MMP-9, MMP-12 polymorphisms among chronic obstructive pulmonary disease and smokers nonchronic obstructive pulmonary disease groups.

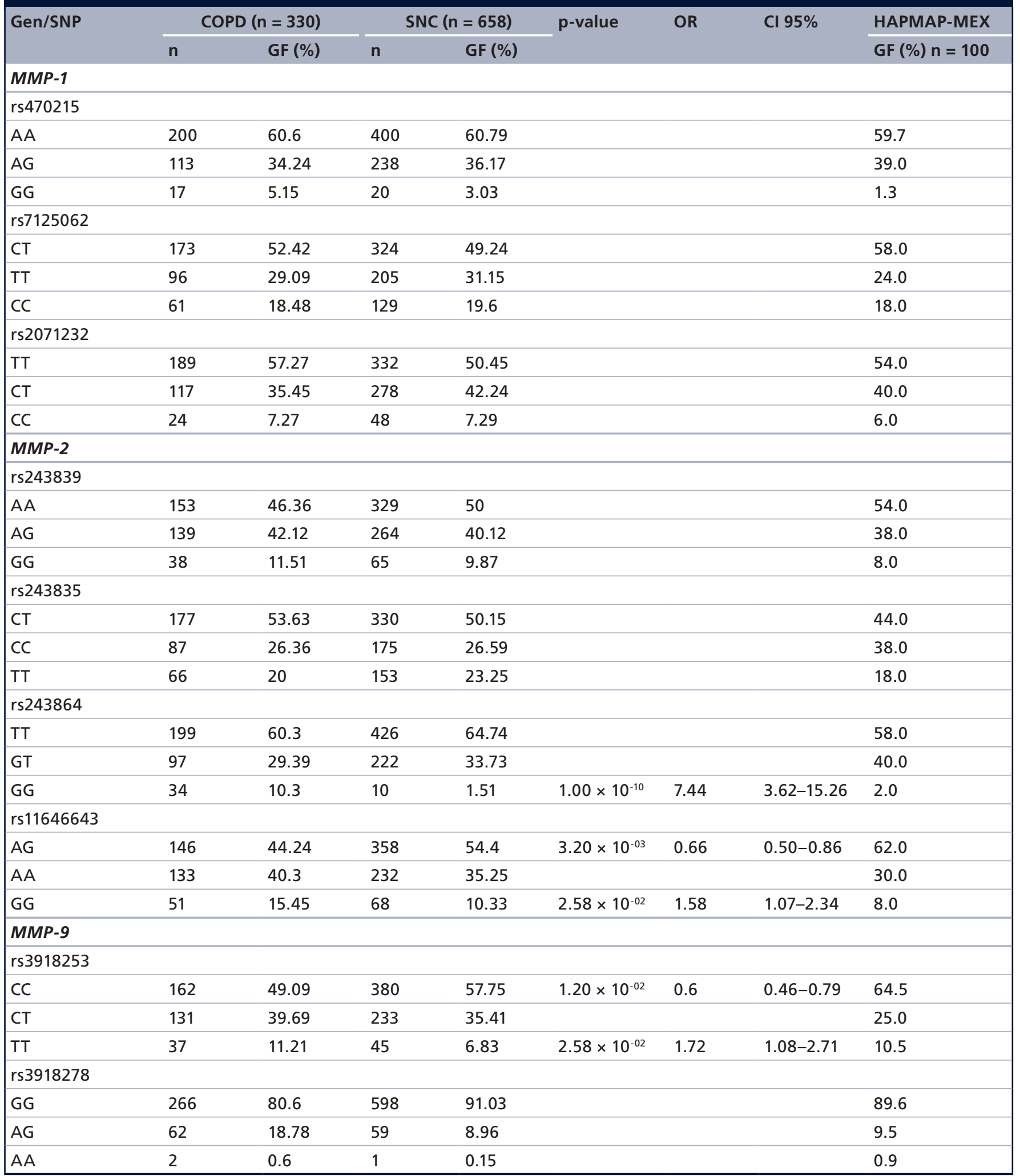


Table 3. Genotype frequencies of MMP-1, MMP-2, MMP-9, MMP-12 polymorphisms among chronic obstructive pulmonary disease and smokers nonchronic obstructive pulmonary disease groups (cont.).

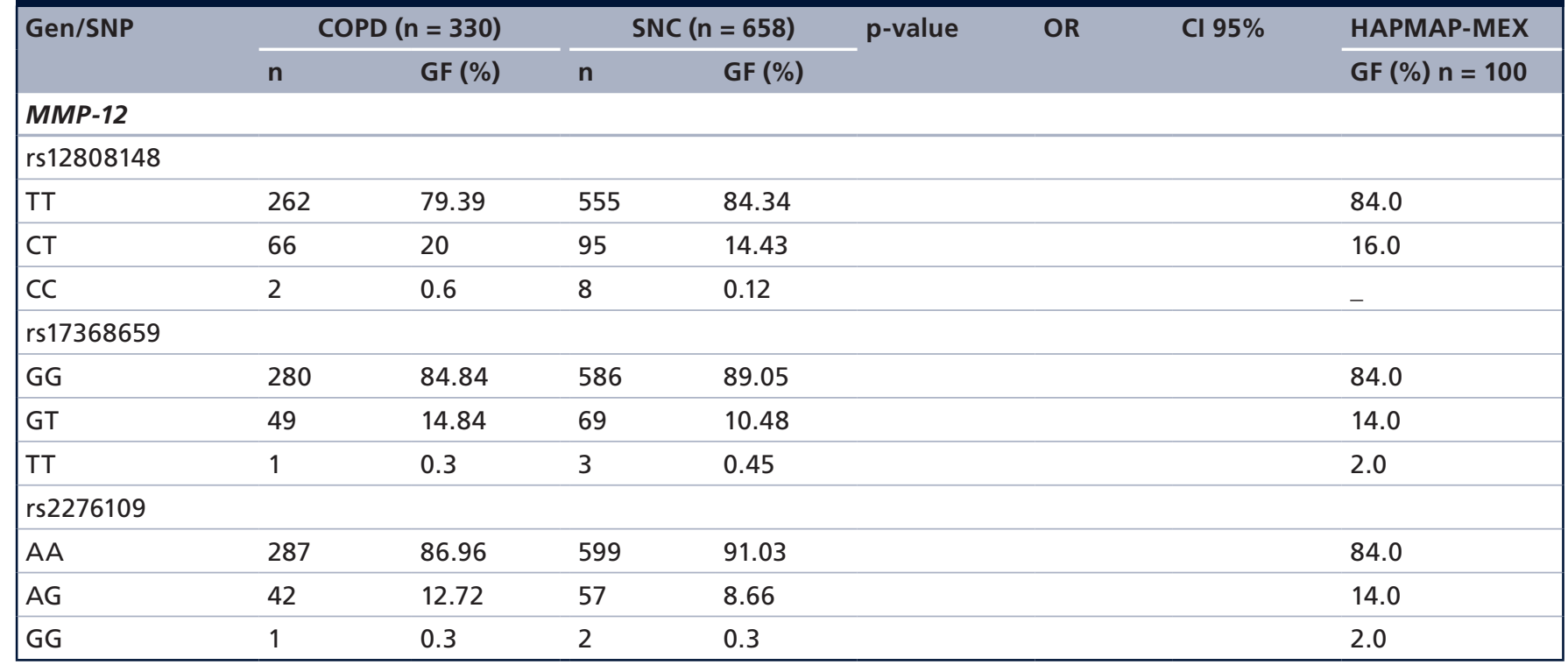

The prevalence of disease is greater in men than in women; in this study, we found a similar pattern (3.07:1, $\mathrm{M}: \mathrm{W})$ to that described in the PLATINO study [25].

In the pathogenesis of COPD, there is an increase in neutrophils and macrophages, innate immunity cells that express proteolytic enzymes such as extracellular matrix metalloproteinases (MMPs), mainly MMP-1, MMP-2, MMP-9 and MMP-12. MMPs contribute to chronic inflammation, the development of COPD and the presence of emphysema [26]. In patients with emphysema, there is increased production of MMP-2 and MMP-9 (gelatinases A and B, respectively) in the lung parenchyma, resulting in degradation and remodeling of this tissue associated with chronic inflammation [2729]. Different studies have evaluated the involvement of genetic factors in the susceptibility and severity of COPD [30-33]; the most clearly associated factor, genetic deficiency of alpha-1 antitrypsin, is highly prevalent among individuals of northern Europe [34]. However, in Mexican mestizos, the frequency of polymorphisms associated with this deficiency is low [35], suggesting the existence of other genetic factors associated with risk.

To date, there are no genetic association studies of rs243864 with COPD; to our knowledge we are the first to demonstrate the strong genetic association of rs11646643 and rs243864 polymorphisms (-790 T/G) with the risk of developing COPD in the Mexican mestizo population. The latter polymorphism is located in the GATA-1 site (CTATCT) of the promoter region of the MMP-2 gene [36], which has binding sites for the transcription factors AP-2, p53, Sp1 and Sp3 [37]. These transcription factors regulate the transcription rate of the gene and, therefore, the expression of the protease. Additionally, rs243864 is a tag SNP of the rs243865 (-1306 C/T) and rs243866 (-1575G/A) polymorphisms [38], which are also found in the gene promoter. Interestingly, we found that the GG genotype of rs243864 has the highest OR value (7.44) among associated SNPs. Another finding was that the TT genotype of the rs3918253 polymorphism of the MMP-9 gene (OR: 1.72) is also associated with the risk of COPD; this genotype is an intronic variant and a tag SNP of the rs3918256 polymorphism, which is reported to not have a genetic association with COPD in the Caucasian population [20]. There are no previous studies of rs3918253 genetic association with COPD; our results are the first to indicate an association of susceptibility of the MMP-9 gene to disease. However, other SNPs in the promoter of the MMP-9 gene have been reported, among which is rs3918242 (-1562 C/T), which has been associated with emphysema in the Japanese population [41]. Furthermore, a meta-analysis conducted by Chen $e t a l$. found that this polymorphism increases the risk of COPD in the Asian population but not in Caucasians [42]. Another study in the Caucasian population found no genetic association of the rs 3918242 polymorphism with loss of lung function [43]. These findings indicate that SNPs have a different impact on different populations. In addition, genetic factors interact with environmental factors to influence individual susceptibility. A similar phenomenon could be taking place with the genotype frequencies of the group of smokers without disease (SNC) compared with those described for HapMap Mexican mestizos. The CT genotype of 


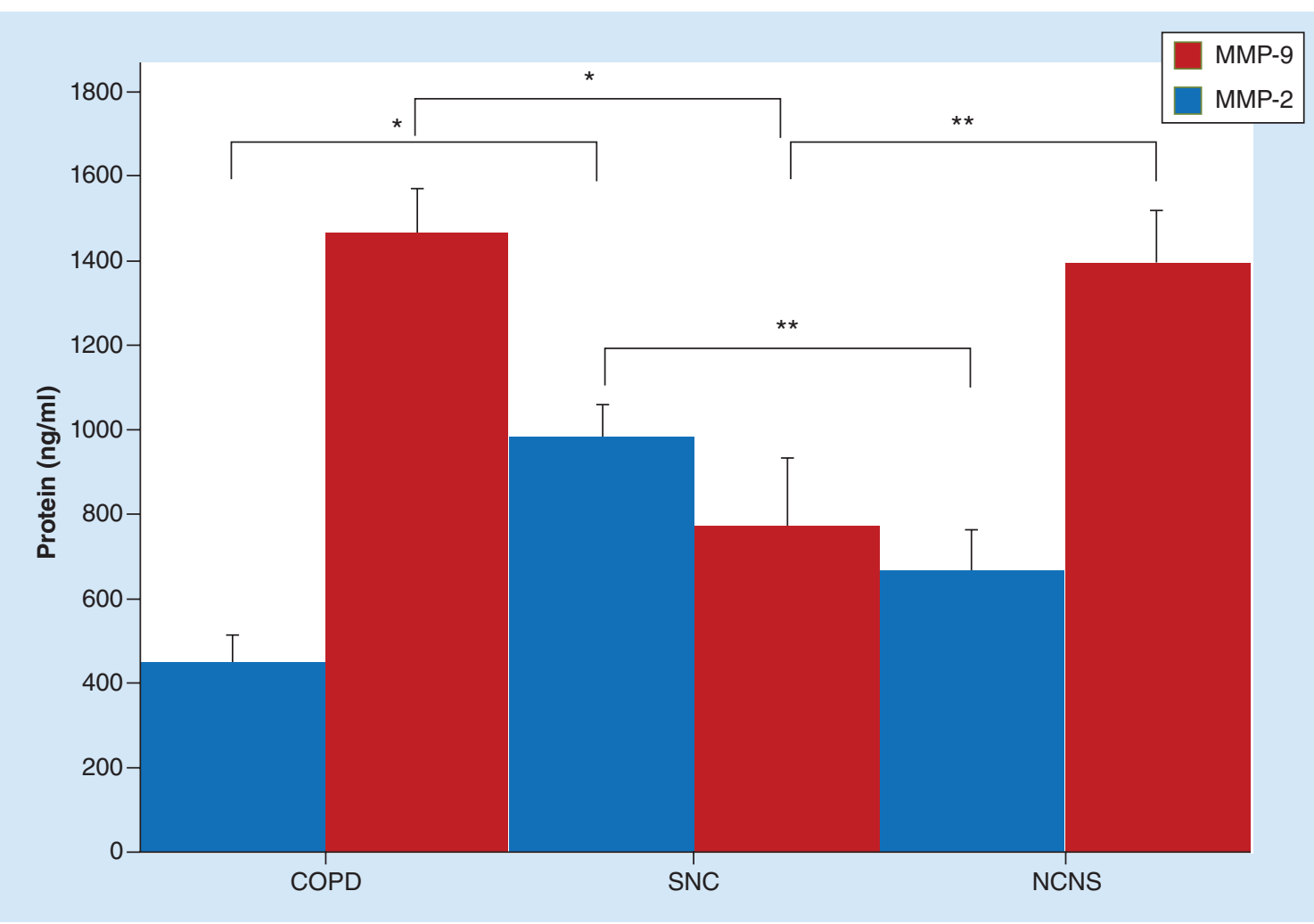

Figure 1. Total MMP-2 and MMP-9 protein levels measured by ELISA in smokers with chronic obstructive pulmonary disease (COPD), smokers without COPD (SNC) and nonsmokers (NCNS). Analysis of variance (ANOVA; Tukey-Kramer's) comparing protein levels between the groups. The results are expressed as the mean \pm SD. ${ }^{*} \mathrm{p}<0.05$ significant difference between COPD and SNC for MMP-2 and MMP-9.

${ }^{* *} p<0.05$ denotes a significant difference between SNC and NCNS for MMP-2 and MMP-9.

rs3918253 in the MMP-9 gene shows a $10 \%$ difference between the two populations ( 35.41 vs $25 \%$ ). However, it should be taken into consideration that for the population and variant consulted in the HapMap project, only 100 Mexican residents were evaluated in Los Angeles (CA, USA), that is, individuals with Mexican ancestry; our study included a total of 658 smokers without COPD. The AG genotype of rs243864 and the CC genotype of rs3918253 of the MMP-2 and MMP-9 genes, respectively, are associated with decreased risk of disease (OR: 0.6); both represent the highest frequency of genotypes, suggesting they could positively influence smokers carrying these alleles. In our study, we found a reduced $\mathrm{FEV}_{1} / \mathrm{FVC}(\%)$ post bronchodilator ratio in homozygous TT carriers for rs3918253 of the MMP9 gene, the same genotype that is associated with risk of COPD (OR: 1.72). These findings indicate some involvement of this polymorphism in the pathogenesis of COPD in our population.

It was recently reported that there is systemic inflammation in patients with COPD [42], which is mediated primarily by an increase in systemic circulation of proinflammatory cytokines [44,45]; one report suggested that MMPs in serum are potential repair biomarkers in emphysema [46]. In our study, the serum levels of the MMP-2 and MMP-9 proteins, both of which are gelatinases from the MMP group, were evaluated in the COPD, SNC and NCNS groups; the MMP-9 protein was related through its function mainly in the remodeling of basement membranes, especially of collagen types I and IV and elastic fibers [47]. In patients with COPD, it was shown that the MMP-9 protein increases in serum and correlates with the serum levels of its major endogenous inhibitor, TIMP-1 [48]. This finding is similar to what occurred in our study, in which we found increased serum levels of MMP-9 protein in the COPD group compared with the serum levels observed in the SNC group. Notably, we did not find any relationship of these levels with genotypes or other variables.

Regarding MMP-2, it is involved in remodeling of the extracellular matrix in airways and lung interstitium by degrading molecules such as collagen type I, III, IV, V, VII and X, gelatin, fibronectin, laminin and aggrecan [49]. In our study, the serum levels of MMP-2 were found to decrease in the COPD group compared with those in the SNC group. Similar to our finding, in 2010, Gosselink et al. found that mRNA expression of the $M M P-2$ gene and activity of gelatinase 
decreases in lung tissue and small airways, related to a decline in FEV1. A second study showed that MMP-2 decreases in bronchial epithelial cells of patients with severe COPD [50], contrary to the reports of SeguraValdez et al. in 2013, who found an increase in the number of alveolar macrophages and epithelial cells labeled with MMP-2 by immunohistochemistry in patients with COPD. MMP-2 has the ability to cleave monocyte chemotactic protein-3 (MCP-3), allowing it to bind to chemotactic receptors 1,2 and 3 without activating them. This feature would suggest that the decrease in MMP-2 contributes to a persistent inflammatory response in COPD by not allowing modification of MCP-3 [50]. Finally, we should consider that cigarette smoke induces expression of other proteinases and MMPs, which despite the decrease in MMP-2 in the COPD group, could ultimately be causing the characteristic damage of the disease $[18,26]$ in a manner independent from MMP-2.

A limitation of our study is that the population of Mexican mestizos by descent has primarily Amerindian and Caucasian genetic contributions in different proportions, which could cause the associated SNP findings to not necessarily be replicated in other populations. We found five SNPs associated with COPD; however, only two SNPs retain association after Bonferroni's correction (rs243864/GG and rs11646643/AG). It is desirable that SNPs associated with COPD in the MMP-2 and $M M P-9$ genes be evaluated in one or more populations by independent groups, particularly in other mestizo populations and thus strengthen the idea that the participation of these SNPs in the risk of COPD is real.

Our results contribute to the knowledge of genetic factors in candidate genes in the development of COPD. Ultimately, trials are required to evaluate these polymorphisms as potential markers of clinical phenotypes of disease, considering that COPD is an inflammatory disease that not only affects the airways but also shows systemic inflammation associated with increased morbidity and mortality.

\section{Future perspective}

Currently, the genetic association studies provide information on the genotype frequencies of SNPs in candidate genes for multifactorial diseases, such as COPD, and seek to know the expression of the gene or protein. Our study measured serum MMP proteins associated with COPD; although unrelated to the genotype or other variables, was found serum levels were modified in the study groups; in the future, next studies should include identification of associated SNPs, gene expression assays, protein allocation and biological function.

\section{Supplementary data}

To view the supplementary data that accompany this paper please visit the journal website at: www.futuremedicine.com/ doi/full/10.2217/BMM.15.75

\section{Financial \& competing interests disclosure}

The authors acknowledge the support received from physicians and technicians from COPD clinic at INER, for confirmation of diagnosis and acquisition of data on lung function. Jazmín Hernández-Montoya acknowledges the scholarship (\#332419) by the Mexican National Council of Science and Technology (CONACYT). This paper constitutes a partial fulfillment for obtaining the JHM's PhD of the Graduate Program in Biological Sciences and Health of the Universidad Autónoma Metropolitana (UAM) at México City. Supported by a research grant from the Instituto Nacional de Enfermedades Respiratorias Ismael Cosío Villegas. Support the resource assigned to INER, managed in LXI Legislatures of the Chamber of Deputies, through its Committee on Equality and Gender, for the budgetary allocation for the Care of Using Wood Associated Diseases in 2012. The authors have no other relevant affiliations or financial involvement with any organization or entity with a financial interest in or financial conflict with the subject matter or materials discussed in the manuscript apart from those disclosed.

No writing assistance was utilized in the production of this manuscript.

\section{Ethical conduct of research}

This protocol was evaluated and accepted by the Science and Research Bioethics Committees of the INER in Mexico. All participants were initially invited to participate, and those who agreed signed a letter of informed consent created for that purpose.

\section{Open access}

This work is licensed under the Creative Commons Attribution-NonCommercial 4.0 Unported License. To view a copy of this license, visit http://creativecommons.org/licenses/bync-nd/4.0/

Executive summary

- Polymorphisms of the MMP-2 and MMP-9 genes are associated with risk of chronic obstructive pulmonary disease in the Mexican mestizo population.

- There are differences in the serum levels of MMP2 and MMP9 proteins between the study groups.

- Our study provides the knowledge that polymorphisms and the proteins associated genes influence the presence of chronic obstructive pulmonary disease. 


\section{References}

Papers of special note have been highlighted as: " of interest

1 Stockley RA. New approaches to the management of COPD. Chest 117(2 Suppl.), 58S-62S (2000).

2 Suki B, Bates JH. Extracellular matrix mechanics in lung parenchymal diseases. Respir. Physiol. Neurobiol. 163(1-3), 33-43 (2008).

3 Suki B, Jesudason R, Sato S et al. Mechanical failure, stress redistribution, elastase activity and binding site availability on elastin during the progression of emphysema. Pulm. Pharmacol. Ther. 25(4), 268-275 (2012).

4 Global Strategy for the Diagnosis. Management, and Prevention of Chronic Obstructive Pulmonary Disease. http://www.goldcopd.org

5 Smith MC, Wrobel JP. Epidemiology and clinical impact of major comorbidities in patients with COPD. Int. J. Chron. Obstruct. Pulmon. Dis. 9, 871-888 (2014).

6 Powell R, Davidson D, Divers J et al. Genetic ancestry and the relationship of cigarette smoking to lung function and per cent emphysema in four race/ethnic groups: a cross-sectional study. Thorax 68(7), 634-642 (2013).

7 Sandford AJ, Silverman EK. Chronic obstructive pulmonary disease. 1: Susceptibility factors for COPD the genotype-environment interaction. Thorax 57(8), 736-741 (2002).

8 Mannino DM, Buist AS. Global burden of COPD: risk factors, prevalence, and future trends. Lancet 370(9589), 765-773 (2007).

9 LØkke A, Lange P, Scharling H, Fabricius P, Vestbo J. Developing COPD: a 25 year follow up study of the general population. Thorax 61(11), 935-9 (2006).

10 Fang C, Wen G, Zhang L et al. An important role of matrix metalloproteinase- 8 in angiogenesis in vitro and in vivo. Cardiovasc. Res. 99(1), 146-155 (2013).

11 Ghajar CM, George SC, Putnam AJ. Matrix metalloproteinase control of capillary morphogenesis. Crit. Rev. Eukaryot. Gene Expr. 18(3), 251-278 (2008).

12 Kessenbrock K, Plaks V, Werb Z. Matrix metalloproteinases: regulators of the tumor microenvironment. Cell 141(1), 52-67 (2010)

13 Manicone AM, McGuire JK. Matrix metalloproteinases as modulators of inflammation. Semin. Cell Dev. Biol. 19(1), 34-41 (2008).

14 Sternlicht MD, Werb Z. How matrix metalloproteinases regulate cell behavior. Annu. Rev. Cell. Dev. Biol. 17, 463-516 (2001).

15 Ohnishi K, Takagi M, Kurokawa Y, Satomi S, Konttinen YT. Matrix metalloproteinase-mediated extracellular matrix protein degradation in human pulmonary emphysema. Lab Invest. 78(9), 1077-1087 (1998).

16 Parks WC, Shapiro SD. Matrix metalloproteinases in lung biology. Respir. Res. 2(1), 10-19 (2001).

17 Greenlee KJ, Werb Z, Kheradmand F. Matrix metalloproteinases in lung: multiple, multifarious, and multifaceted. Physiol. Rev. 87(1), 69-98 (2007).
18 Kumar M, Phougat N, Ruhil S, Dhankhar S, Balhara M, Chhillar AK. Genomics of chronic obstructive pulmonary disease (COPD); exploring the SNPs of protease-antiprotease pathway. Curr. Genomics 14(3), 204-213 (2013).

19 Hirano K, Sakamoto T, Uchida Y et al. Tissue inhibitor of metalloproteinases-2 gene polymorphisms in chronic obstructive pulmonary disease. Eur. Respir. J. 18(5), 748-752 (2001).

20 Haq I, Chappell S, Johnson SR et al. Association of MMP2 polymorphisms with severe and very severe COPD: a case control study of MMPs-1, 9 and 12 in a European population. BMC Med. Genet. 11, 7 (2010).

- It was found that the rs3918256 polymorphism is associated with COPD in the Caucasian population. This polymorphism is a tag SNP of rs3918253, which is associated with COPD risk in the Mexican mestizo population.

21 Lee SY, Kim MJ, Kang HG et al. Polymorphisms in matrix metalloproteinase-1, -9 and -12 genes and the risk of chronic obstructive pulmonary disease in a Korean population. Respiration 80(2), 133-138 (2010).

22 Aminuddin F, Hackett TL, Stefanowicz D et al. Nitric oxide synthase polymorphisms, gene expression and lung function in chronic obstructive pulmonary disease. BMC Pulm. Med. 13, 64 (2013).

23 Pérez-Rubio G, Jiménez-Valverde LO, Ramírez-Venegas A et al. Prevalence of alpha-1 antitrypsin high-risk variants in Mexican mestizo population and their association with lung function values. Arch. Bronconeumol. 51(2), 80-85 (2015).

24 Reséndiz-Hernández JM, Sansores RH, Hernández-Zenteno $\mathrm{RJ}$ et al. Identification of genetic variants in the TNF promoter associated with COPD secondary to tobacco smoking and its severity. Dove Medical 10(1), 1241-1251 (2015).

25 Lopez Varela MV, Montes de Oca M, Halbert RJ et al. Sex-related differences in COPD in five Latin American cities: the PLATINO study. Eur. Respir. J. 36(5), 1034-1041 (2010).

26 Abboud RT, Vimalanathan S. Pathogenesis of COPD. Part I. The role of protease-antiprotease imbalance in emphysema. Int. J. Tuberc. Lung Dis. 12(4), 361-367 (2008).

27 Finlay GA, O’Driscoll LR, Russell KJ et al. Matrix metalloproteinase expression and production by alveolar macrophages in emphysema. Am. J. Respir. Crit. Care Med. 156(1), 240-247 (1997).

28 Hogg JC, Chu F, Utokaparch S et al. The nature of smallairway obstruction in chronic obstructive pulmonary disease. N. Engl. J. Med. 350 (26), 2645-2653 (2004).

29 Russell RE, Culpitt SV, DeMatos C et al. Release and activity of matrix metalloproteinase- 9 and tissue inhibitor of metalloproteinase-1 by alveolar macrophages from patients with chronic obstructive pulmonary disease. Am. J. Respir. Cell Mol. Biol. 26(5), 602-609 (2002).

30 Cheng SL, Yu CJ, Yang PC. Genetic polymorphisms of cytochrome p450 and matrix metalloproteinase in chronic obstructive pulmonary disease. Biochem. Genet. 47(7-8), 591-601 (2009). 
31 Zhou H, Wu Y, Jin Y et al. Genetic polymorphism of matrix metalloproteinase family and chronic obstructive pulmonary disease susceptibility: a meta-analysis. Sci. Rep. 3, 2818 (2013).

32 Tesfaigzi Y, Myers OB, Stidley CA et al. Genotypes in matrix metalloproteinase 9 are a risk factor for COPD. Int. J. Chron. Obstruct. Pulmon. Dis. 1(3), 267-278 (2006).

33 de Serres FJ, Blanco I, Fernández-Bustillo E. PI S and PI $\mathrm{Z}$ alpha-1 antitrypsin deficiency worldwide. A review of existing genetic epidemiological data. Monaldi Arch. Chest Dis. 67(4), 184-208 (2007).

34 Price SJ, Greaves DR, Watkins H. Identification of novel, functional genetic variants in the human matrix metalloproteinase- 2 gene: role of $S \mathrm{p} 1$ in allele-specific transcriptional regulation. J. Biol. Chem. 276(10), 75497558 (2001)

35 Qin $\mathrm{H}$, Sun $\mathrm{Y}$, Benveniste EN. The transcription factors Sp1, Sp3, and AP-2 are required for constitutive matrix metalloproteinase- 2 gene expression in astroglioma cells. J. Biol. Chem. 274(41), 29130-29137 (1999).

36 Vask A, Goldbergová M, Izakovicová Hollá L et al. A haplotype constituted of four MMP-2 promoter polymorphisms (-1575G/A, -1306C/T, $-790 \mathrm{~T} / \mathrm{G}$ and $-735 \mathrm{C} / \mathrm{T})$ is associated with coronary triple-vessel disease. Matrix Biol. 22(7), 585-591 (2004).

37 Morgan AR, Han DY, Thompson JM, Mitchell EA, Ferguson LR. Analysis of MMP2 promoter polymorphisms in childhood obesity. BMC Res. Notes 4, 253 (2011).

38 Hua Y, Song L, Wu N et al. Polymorphisms of MMP-2 gene are associated with systolic heart failure prognosis. Clin. Chim. Acta 404(2), 119-123 (2009).

39 Ito I, Nagai S, Handa T et al. Matrix metalloproteinase-9 promoter polymorphism associated with upper lung dominant emphysema. Am. J. Respir. Crit. Care Med. 172(11), 1378-1382 (2005).

40 Chen L, Wang T, Liu L, Shen Y, Wan C, Wen F. Matrix metalloproteinase-9 - $1562 \mathrm{C} / \mathrm{T}$ promoter polymorphism confers risk for COPD: a meta-analysis. PLoS ONE 8(3), e60523 (2013).

41 Joos L, He JQ, Shepherdson MB et al. The role of matrix metalloproteinase polymorphisms in the rate of decline in lung function. Hum. Mol. Genet. 11(5), 569-576 (2002). Erratum in: Hum. Mol. Genet. 12(7), 803-804 (2003).

42 Agustí AG, Noguera A, Sauleda J, Sala E, Pons J, Busquets $\mathrm{X}$. Systemic effects of chronic obstructive pulmonary disease. Eur. Respir. J. 21(2), 347-360 (2003).

- Refers to systemic inflammation in COPD and suggested that MMPs in serum are potential repair biomarkers in emphysema, in our study the proteins were evaluated.

43 Di Francia M, Barbier D, Mege JL, Orehek J. Tumor necrosis factor-alpha levels and weight loss in chronic obstructive pulmonary disease. Am. J. Respir. Crit. Care Med. 150(5 Pt 1), 1453-1455 (1994).

44 Eid AA, Ionescu AA, Nixon LS et al. Inflammatory response and body composition in chronic obstructive pulmonary disease. Am. J. Respir. Crit. Care Med. $164(8 \mathrm{Pt} 1)$, 1414-1418 (2001)

45 Pinto-Plata V, Casanova C, Müllerova H et al. Inflammatory and repair serum biomarker pattern: association to clinical outcomes in COPD. Respir. Res. 13, 71 (2012).

46 SkjØt-Arkil H, Clausen RE, Nguyen QH et al. Measurement of MMP-9 and -12 degraded elastin (ELM) provides unique information on lung tissue degradation. BMC Pulm. Med. 12, 34 (2012).

47 Brajer B, Batura-Gabryel H, Nowicka A, KuznarKaminska B, Szczepanik A. Concentration of matrix metalloproteinase-9 in serum of patients with chronic obstructive pulmonary disease and a degree of airway obstruction and disease progression. J. Physiol. Pharmacol. 59(Suppl. 6), 145-152 (2008).

48 Nagase H. Metalloproteases. Curr. Protoc. Protein Sci. 2, Chapter 21, Unit 21.4 (2001).

49 Perotin JM, Adam D, Vella-Boucaud J et al. Delay of airway epithelial wound repair in COPD is associated with airflow obstruction severity. Respir. Res. 15(1), 151 (2014).

50 McQuibban GA, Gong JH, Tam EM, McCulloch CA, Clark-Lewis I, Overall CM. Inflammation dampened by gelatinase A cleavage of monocyte chemoattractant protein-3. Science 289(5482), 1202-1206 (2000). 